Revisão / Review

\title{
Deficiência de ferro no feto e no recém-nascido
}

Iron deficiency in the fetus and newborn

Maria Renata T. Chopard ${ }^{1}$

Maurício Magalhães ${ }^{2}$

Paula Bruniera ${ }^{3}$

\begin{abstract}
A principal causa de anemia no feto é a doença hemolítica do recém-nascido ( $R N)$. As gestantes anêmicas na sua forma moderada não acarretam baixos estoques de ferro no concepto, porém podem evoluir para o trabalho de parto prematuro e $R N$ com baixo peso ao nascer. O ferro é transportado para o feto por via transplacentária, principalmente durante o terceiro trimestre de gestação. A deficiência de ferro não ocorre no periodo neonatal, porém os prematuros e ou $R N$ com baixo peso constituem o principal grupo de risco para desenvolver a deficiência de ferro. Nos RN nascidos a termo podemos observar uma deficiência de ferro naqueles que sofreram ressecção cirúrgica do duodeno devido à malformação congênita. A fim de evitarmos a deficiência de ferro neste grupo de risco, indica-se a suplementação de ferro a partir dos 30 dias de vida. $A$ via de administração preferencial é a enteral, apesar de sabermos que no prematuro ocorre uma deficiencia do controle da absorção do ferro. O complexo de ferro polimaltosado e o ferro aminoquelado são os de escolha para a profilaxia da deficiência de ferro em prematuros. A via endovenosa é segura e não acarreta piora das lesões causadas pela ação oxidativa do ferro em prematuros. Rev. Bras. Hematol. Hemoter. 2010;32(Supl.2):32-37.
\end{abstract}

Palavras-chave: Anemia; deficiência de ferro; feto; recém-nascido de baixo peso; recém-nascido; prematuro; ferro.

\section{Introdução}

A partir da nona semana de idade pós-concepcional inicia-se o período fetal, o qual se estende até o nascimento. Durante esta fase da vida não ocorre a anemia secundária à deficiência de ferro.

A principal causa de anemia no feto é a anemia hemolítica. Dentre as anemias hemolíticas podemos citar como a mais freqüente a anemia secundária à incompatibilidade Rh. Lembramos, ainda, as anemias secundárias às infecções congênitas e a parvovirose.
A definição de recém-nascido ( $\mathrm{RN}$ ) engloba todos os conceptos nascidos vivos com idade até 28 dias. Esta classificação não leva em conta a idade gestacional ao nascimento; portanto, devemos ter especial consideração com os recém-nascidos prematuros que poderão atingir 28 dias de vida antes mesmos, de terem idade gestacional corrigida de 40 semanas.

Levando em consideração a definição acima, podemos afirmar que a deficiência de ferro não ocorre no período neonatal, porém os $\mathrm{RN}$ prematuros e os $\mathrm{RN}$ de baixo peso constituem o principal grupo de risco para desenvolver a

\footnotetext{
${ }_{2}^{I}$ Neonatologista. Assistente do Serviço de Neonatologia do Departamento de Pediatria da Santa Casa de São Paulo - São Paulo-SP.

${ }^{2}$ Neonatologista. Professor da FCM da Santa Casa de São Paulo. Chefe do Serviço de Neonatologia do Departamento de Pediatria da Santa Casa de São Paulo- São Paulo-SP

${ }^{3}$ Onco-hematologista pediátrica. Professora da FCM da Santa Casa de São Paulo. Chefe do Serviço de Onco-hematologia do Departamento de Pediatria da Santa Casa de São Paulo - São Paulo-SP.
}

Santa Casa de São Paulo - São Paulo-SP.

Correspondência: Maria Renata Tollio Chopard

Santa Casa de Misericórdia de São Paulo

Rua Cesário Motta Júnior, 112 - Santa Cecília

01221-020 - São Paulo-SP - Brasil

Tel: (55 11)2176-7000 R: 5667

E-mail: rechopard@uol.com.br

Doi: $10.1590 /$ S1516-84842010005000051 
deficiência de ferro. Nos RN nascidos a termo podemos observar uma deficiência de ferro naqueles que sofreram ressecção cirúrgica do duodeno devido à mal-formação congênita.

A Organização Pan-Americana de Saúde - OPAS estima que pelo menos $30 \%$ das gestantes sofrem de anemia e que há uma maior probabilidade dessas mulheres terem bebês de baixo peso e parto prematuro. ${ }^{1,2}$

A deficiência de ferro ou anemia moderada na gestação não interfere no status de ferro do RN. ${ }^{3}$

Abordaremos, neste artigo, os $\mathrm{RN}$ prematuros e de baixo peso.

\section{Fisiopatologia da anemia no feto e no recém-nascido}

\section{O sistema hematopoético do feto}

A eritropoese inicia-se em torno de 14 dias de idade pós-concepcional, quando os eritrócitos primitivos do embrião começam a ser produzidos no saco vitelino. Ao redor de cinco semanas, o fígado passa a ser o principal órgão produtor de glóbulos vermelhos. Entre a nona e a décima primeira semana pós-concepção, já se evidencia eritropoese na medula óssea, porém ela permanece relativamente inativa até o termo. A mudança do sítio de produção dos eritrócitos para a medula óssea faz-se entre o final da gestação e as primeiras semanas de vida pós-natal. ${ }^{4-6}$

No feto, a eritropoetina pode ser encontrada já na $19^{\mathrm{a}}$ semana de idade gestacional. ${ }^{7} \mathrm{Na}$ vida fetal, é produzida principalmente pelos macrófagos do parênquima hepático. A partir do terceiro trimestre de gestação até algumas semanas após o nascimento, ocorre, de forma gradual, a troca do sítio de produção da eritropoetina para as células peritubulares, possivelmente fibroblastos do córtex renal. ${ }^{8}$ É desconhecido o mecanismo desencadeante desta mudança.

O ferro é um nutriente essencial para o organismo, já que está envolvido em diversos processos metabólicos vitais, destacando o transporte de oxigênio e a produção de energia.

O ferro é transportado para o feto por via transplacentária, principalmente durante o terceiro trimestre de gestação. Esta transferência é inicialmente realizada por uma endocitose, mediada por um receptor do complexo da transferrina sérica, no interior do sinciciotrofoblasto. Nas células placentárias, ocorre a liberação do ferro e o retorno da apoproteína para a circulação materna. ${ }^{5,9}$

A incorporação de ferro pelo feto é proporcional ao seu peso corporal. Como o mais importante aumento de peso fetal ocorre no último trimestre da vida intrauterina, a criança prematura e a que sofreu retardo de crescimento intrauterino, resultando num baixo peso ao nascer, acumularão menos ferro em comparação ao recém-nascido a termo e de peso adequado para a idade gestacional. ${ }^{4}$

$\mathrm{Na}$ vida fetal, o acúmulo de ácido fólico, no fígado, ocorre no final do terceiro trimestre. Desta forma, os prematuros nascem com menores reservas e maior probabilidade de desenvolver sua deficiência.

\section{Anemia fisiológica do recém-nascido}

A partir do nascimento, o RN sofre importantes modificações do quadro hematológico com a finalidade de se adaptar ao meio extrauterino. Observa-se nas primeiras semanas de vida uma queda acentuada, autolimitada, da taxa de hemoglobina, comum a todos os lactentes. Trata-se de uma queda fisiológica, cujo pico ocorre na oitava semana de vida. A administração de ferro nesta ocasião não impede nem atenua essa queda.

Em torno da oitava e décima segunda semana de vida ocorre a retomada de produção da eritropoese e o ferro armazenado será reutilizado, sendo mínimo o requerimento de ferro exógeno.

A velocidade de crescimento nos primeiros meses, porém, poderá provocar esgotamento dos estoques de ferro em torno do quarto ao sexto mês de vida para o $\mathrm{RN}$ a termo e com peso adequado para a idade gestacional. Após esse período, o ferro exógeno tem importância fundamental na prevenção da anemia. É nessa época que a suplementação com ferro eleva a concentração de hemoglobina. ${ }^{10}$

\section{Anemia do prematuro}

Logo após o parto verifica-se um aumento dos níveis séricos de hemoglobina e hematócrito, em virtude da redistribuição dos fluidos corporais, com saída de líquido do compartimento intravascular para o extravascular.

Após esta elevação, ocorre queda gradativa da hemoglobina e do hematócrito. No recém-nascido pré-termo (RNPT), esta queda é mais precoce, ao redor da sexta à oitava semana de idade pós-natal; além disso, o seu nadir é mais acentuado, sendo, nos prematuros com peso de nascimento entre $1.000 \mathrm{~g}$ e $1.500 \mathrm{~g}$, em torno de $8 \mathrm{~g} / \mathrm{dL}$ de $\mathrm{Hb}$, enquanto nos abaixo de $1.000 \mathrm{~g}$, chega a $7 \mathrm{~g} / \mathrm{dL} .^{11,12}$ Esta anemia é normocítica e normocrômica.

As razões para a ocorrência da anemia no prematuro são múltiplas. Na sala de parto, podemos citar como fator determinante do hematócrito no recém-nascido o tempo que se leva para fazer a ligadura do cordão umbilical. O retardo do clampeamento do cordão umbilical ocasiona um aumento do volume sanguíneo logo após o nascimento e, após 48 horas, nota-se um hematócrito mais elevado nesses recémnascidos, ${ }^{13}$ além de promoverem estoques de ferro mais alto. ${ }^{14,15}$

Ao nascimento, as taxas de hemoglobina do sangue do cordão umbilical giram ao redor de 17,5 $\pm 1,6 \mathrm{~g} / \mathrm{dL}$. No primeiro e segundo dias de vida, há um aumento da concentração da hemoglobina, decorrente da hemoconcentração transitória, resultante da baixa oferta hídrica e da redistribuição do volume plasmático. A partir da primeira semana de vida, ocorre uma diminuição progressiva da hemoglobina. ${ }^{16}$ 
Durante o período neonatal ocorre também maior destruição dos glóbulos vermelhos, pois a meia vida dos eritrócitos, nesta faixa etária, é menor que setenta dias. ${ }^{17}$ Além disso, existe uma grande expansão do volume sanguíneo, secundária ao rápido crescimento somático do prematuro, levando à hemodiluição. A queda na concentração de hemoglobina, no entanto, principia-se com a diminuição da massa eritroide circulante. ${ }^{16}$

Esta queda na concentração de hemoglobina ocorre por diminuição da eritropoese consequente ao maior aporte de oxigênio $\left(\mathrm{O}_{2}\right)$, após o nascimento, o que facilita a oxigenação tecidual, ocasionando diminuição da eritropoetina. ${ }^{18,19}$ A eritropoetina apresenta um grande aumento entre quatro e seis semanas de idade pósnatal, demonstrando a sua capacidade de estimular a eritropoese diante de certo grau de anemia. ${ }^{19}$ Este aumento da atividade eritropoética é evidenciado pela reticulocitose. Ao redor de cinco meses de idade pós-natal, o valor médio da hemoglobina equivale ao do recém-nascido a termo. ${ }^{17}$

Frente à necessidade de monitorização laboratorial dos prematuros, principalmente nos primeiros dias de vida, constatou-se que a flebotomia tem sido uma das principais responsáveis pela anemia da prematuridade. Estima-se que entre $10 \%$ a $15 \%$ do volume sanguíneo dos prematuros gravemente enfermos sejam removidos para realização de exames laboratoriais, nos primeiros dias de vida. ${ }^{5}$

A deficiência de ferro desempenha papel secundário na anemia da prematuridade nos primeiros dois meses de vida. Após nascimento, os estoques de ferro no prematuro são consumidos rapidamente nas primeiras semanas de vida. Esta diminuição dos estoques está relacionada às perdas sanguíneas no período perinatal ou espoliação para coleta de exames laboratoriais (remoção de $2 \mathrm{~mL}$ de sangue corresponde a $1 \mathrm{mg}$ de ferro), ${ }^{19}$ ao aumento da eritropoese e ao rápido desenvolvimento somático. ${ }^{10}$ Além disso, o transporte intestinal de ferro não responde ao status de ferro, este sistema de controle se desenvolve na infância mais tardiamente. $^{20}$

\section{Repercussões clínicas}

As manifestações clínicas da anemia do prematuro são inespecíficas. Os principais sinais e sintomas são: hipoatividade, apneia, ${ }^{21,22}$ respiração periódica, bradicardia/taquicardia, ${ }^{21}$ taquipneia, baixo ganho ponderal, ${ }^{16} \mathrm{e}$ abertura de canal arterial.
Tabela 1. Valores hematológicos normais

\begin{tabular}{|c|c|c|c|c|c|c|}
\hline \multicolumn{2}{|c|}{ IG semanas } & $\begin{array}{c}\text { Sangue de } \\
\text { cordão } \\
\text { no RNT }\end{array}$ & D1 & D3 & D7 & D14 \\
\hline 14,5 & 15,0 & 16,8 & 18,4 & 17,8 & 17,0 & 16,8 \\
\hline 45,0 & 47,0 & 53 & 58 & 55 & 54 & 52 \\
\hline 4,0 & 4,4 & 5,25 & 5,8 & 5,6 & 5,2 & 5,1 \\
\hline 120 & 118 & 107 & 108 & 99 & 98 & 96 \\
\hline 40 & 38 & 34 & 35 & 33 & 32.5 & 31,5 \\
\hline 31 & 32 & 31,7 & 32,5 & 33 & 33 & 33 \\
\hline $5-10$ & $3-10$ & $3-7$ & $3-7$ & $1-3$ & $0-1$ & $0-1$ \\
\hline & & 290.000 & 192.000 & 213.000 & 248.000 & 252000 \\
\hline
\end{tabular}

Tabela 2. Valores médios de hemoglobina de acordo como peso de nascimento

\begin{tabular}{ccccccccc}
\hline semanas & 3 dias & 1 sem & 2 sem & 3 sem & 4 sem & 6 sem & 8 sem & 10 sem \\
\hline $\begin{array}{c}<1.500 \mathrm{~g} \\
(28-32 \mathrm{sem})\end{array}$ & 17,5 & 15,5 & 13,5 & 11,5 & 10,0 & 8,5 & 8,5 & 9,0 \\
$\begin{array}{c}1.500-2.000 \mathrm{~g} \\
(32-36 \mathrm{sem})\end{array}$ & 19,0 & 16,5 & 14,5 & 13,0 & 12,0 & 9,5 & 9,5 & 9,5 \\
$\begin{array}{c}2.000-2.500 \mathrm{~g} \\
(36-40 \mathrm{sem}) \\
>2.500 \mathrm{~g}\end{array}$ & 19,0 & 16,5 & 15,0 & 14,0 & 12,5 & 10,5 & 10,5 & 11,0 \\
$($ termo $)$ & 19,0 & 17,0 & 15,5 & 14,0 & 12,5 & 11,0 & 11,5 & 12,0 \\
\hline
\end{tabular}

* dados não publicados de Oski, FA e Williams M, in Avery. 24

Como já foi discutida anteriormente, a anemia é um processo fisiológico no recém-nascido. A anemia é normocítica e normocrômica.

Os níveis de hemoglobina e hematócrito diferem de acordo com o tempo de vida do RN. Nas Tabelas 1 e 2 podemos observar as alterações. ${ }^{23,24}$

Sendo a anemia um processo fisiológico no recém-nascido, os valores hematimétricos baixos serão preocupantes somente se levarem alguma repercussão clínica no recémnascido prematuro (RNPT).

Convém ressaltar a importância da contagem de reticulócitos no sangue periférico, no acompanhamento da evolução da anemia fisiológica do prematuro, pois um aumento do número de reticulócitos implica um retorno da atividade eritropoética e, portanto, o início da recuperação da anemia.

Devemos lembrar que valores do volume corpuscular médio (VCM) abaixo de $80 \mu^{3}$, ao nascimento, sugerem microcitose secundária à talassemia-minor.

Para analisar o status de ferro no recém-nascido utilizamos principalmente a concentração sérica de ferritina, que é um indicador precoce do status do estoque de ferro. $\mathrm{O}$ valor normal aproximado em crianças entre 6 a 24 meses é 
de $30 \mathrm{ng} / \mathrm{mL}(100 \pm 60 \mathrm{ng} / \mathrm{mL})$; abaixo de $10 \mathrm{ng} / \mathrm{mL}$ a anemia já é manifesta. A ferritina se altera frente a processos inflamatórios, dificultando a interpretação real do status do ferro no organismo. Durante o período neonatal, consideramos valores de ferritina abaixo de $100 \mathrm{ng} / \mathrm{mL}^{9,25}$ indicativos de deficiência de ferro, sendo indicada a utilização de doses terapêuticas de reposição de ferro.

A dosagem do receptor sérico de transferrina (sTfR) representa uma medida quantitativa da eritropoese total e determina o grau de deficiência tecidual de ferro. $\mathrm{O}$ aumento do sTfR indica anemia na carência de ferro. ${ }^{26,27}$ É um bom parâmetro para diagnosticar a anemia ferropriva, mesmo quando está acompanhada de doenças crônicas inflamatórias, superando a especificidade da ferritina. ${ }^{26-28}$ No nosso meio ainda não é realizado de forma rotineira, devido ao seu alto custo.

Outros métodos laboratoriais podem ser realizados para se avaliar o ferro; dentre eles destacamos a saturação de transferrina, a capacidade total de ligação do ferro, a protorporfirina eritrocitária e o ferro sérico.

\section{Tratamento e profilaxia}

Transfusão de concentrado de hemáceas

A indicação terapêutica da correção da anemia com concentrado de hemáceas depende das repercussões clínicas que o prematuro apresenta, secundárias aos baixos níveis séricos de hemoglobina e hematócrito.

O tratamento clássico da anemia da prematuridade sintomática é a transfusão de concentrado de glóbulos vermelhos, em pequenos volumes ( $10 \mathrm{a} 15 \mathrm{~mL} / \mathrm{kg}$ ).

A transfusão sanguínea não é um procedimento isento de riscos, podendo apresentar diversas complicações infecciosas ou não infecciosas. Nos Estados Unidos, estima-se que o risco de adquirir o vírus da Síndrome da Imunodeficiência Adquirida seja de 1:493.000; para o vírus da hepatite $C$ é de 1:103.000 e para o vírus da hepatite $B$ é de 1: 64.000. Além das infecções virais, a infecção bacteriana é responsável por $16 \%$ dos casos de transfusões fatais. ${ }^{29} \mathrm{Em}$ relação às complicações não infecciosas, a sobrecarga hídrica e consequente insuficiência cardíaca congestiva são mais preocupantes em prematuros, principalmente os extremos. Além disso, podem ocorrer distúrbios ácido-básicos, distúrbios eletrolíticos, principalmente hipercalemia e hipocalcemi $\mathrm{a}^{22} \mathrm{e}$ aumento dos radicais livres levando à injúria tecidual. ${ }^{30}$ Felizmente, as reações aloimunes e hemolíticas agudas não são encontradas no período neonatal. ${ }^{29}$

Atualmente, as unidades de terapia intensiva neonatais adotam critérios restritos para a prática transfusional, ${ }^{25,31,32}$ com o intuito de minimizar a exposição dos prematuros de extremo baixo peso aos múltiplos doadores. Outra medida auxiliar é a utilização do programa de doador único que possibilita a utilização de uma bolsa de sangue mais de uma vez para o mesmo paciente.
Eritropoetina recombinante humana (rHuEPO)

No RNPT existe uma diminuição dos níveis séricos da eritropoetina sugerindo uma participação no desenvolvimento da anemia da prematuridade. A partir daí, vários estudos têm sido realizados, utilizando a r-HuEPO com o objetivo de diminuir as necessidades das transfusões sanguíneas nos neonatos prematuros. ${ }^{25,33} \mathrm{O}$ sucesso do uso da r-huEPO foi inicialmente documentado em indivíduos portadores de IRC. Apesar dos resultados promissores ainda não existe consenso na literatura mundial.

O papel da eritropoetina é diminuir o número de transfusões sanguíneas e o número de prematuros transfundidos dentro da unidade de terapia intensiva neonatal. A eritropoetina, quando indicada, deve ser utilizada após o sétimo dia de idade pós-natal, ${ }^{34,35}$ quando o hematócrito atingir valor inferior a $40 \%$. Não existe uma dose preconizada, mas doses entre 500 a 1.200 UI obtiveram bons resultados e se mostraram seguras. ${ }^{25,36}$

Devido ao estímulo eritropoético causado pela medicação, é indicada a suplementação de ferro de $2 \mathrm{mg} / \mathrm{kg} / \mathrm{dia}$, concomitante ao início da eritropoetina, ou o mais precoce possível. O fator limitante da introdução precoce do ferro é o jejum e/ou a baixa ingesta calórica por via gástrica; neste caso pode ser utilizado o ferro endovenoso. ${ }^{37}$

\section{Ácido fólico}

A reposição de ácido fólico é indicada a partir de 14 dias de idade pós-natal para todos os prematuros com peso inferior a $1.500 \mathrm{~g}$ e tem como objetivo prevenir a anemia megaloblástica. A dose de folato recomendada é de $25-50 \mu \mathrm{g} / \mathrm{dL} .{ }^{38}$

\section{Ferro}

A profilaxia primária da anemia da deficiência de ferro no prematuro e no RN de baixo peso é evidentemente a prevenção do trabalho de parto prematuro e das doenças clínicas maternas que levam ao baixo peso do $\mathrm{RN}$ ao nascer, como, por exemplo, a hipertensão arterial.

A profilaxia secundária já se inicia com a introdução da dieta. Neste momento, a dieta preferencial é o leite materno, mas devido à baixa concentração de ferro no leite e a alta necessidade deste elemento pelo prematuro, utilizamos substâncias suplementares, chamadas de aditivos do leite materno. Vinte mililitros $(\mathrm{mL})$ de leite materno contêm $0,012 \mathrm{mg}$ de ferro e $1 \mu \mathrm{g}$ de ácido fólico; após a adição de $1 \mathrm{~g}$ deste aditivo passamos a ter $0,29 \mathrm{mg}$ de ferro e $11 \mu \mathrm{g}$ de ácido fólico.(http:/ /www.downslivre.com/2009//04/manual-de-medicamentos produtos. html e http://www.nestle.com.br/nutrição).

$\mathrm{Na}$ impossibilidade de alimentarmos o RN com leite materno, utilizamos as fórmulas específicas para prematuros existentes no mercado. ${ }^{39}$

O ferro é indicado para todos os prematuros e RN com baixo peso a partir de trinta dias de vida. Conforme visto anteriormente, a anemia do prematuro é normocítica e normo- 
crômica, porém ela pode evoluir para uma anemia associada à deficiência de ferro. A suplementação de ferro iniciada no segundo mês de vida tem como objetivo evitar a anemia ferropriva.

Atualmente, estudos estão sendo realizados a respeito da introdução precoce de ferro, iniciada ao redor da segunda semana de vida, quando atingimos um aporte de $100 \mathrm{~mL} / \mathrm{kg} / \mathrm{d}$ por via enteral.$^{40} \mathrm{~A}$ introdução precoce apresentou boa tolerabilidade e não aumentou os riscos de retinopatia do prematuro e doença pulmonar crônica. Estudos são contraditórios em relação a atingir estoques de ferro superiores em relação à suplementação tradicional. ${ }^{40,41}$

A recomendação dada pelo Ministério da Saúde para a suplementação de ferro em RN de baixo peso segue as diretrizes da Sociedade Brasileira de Pediatria (Quadro 1). Acessível em http://nutricao.saude.gov.br/documentos/ manual_ferro.pdf e http://www.sbp.com.br/img/manuais/ manual_alim_dc_nutrologia.pdf.

Quadro 1. Recomendação da Sociedade Brasileira de Pediatria

RNT

- Em aleitamento materno: $6^{\circ}$ ao $24^{\circ}$ mês ....................... $1 \mathrm{mg} / \mathrm{kg} / \mathrm{d}$

- Em aleitamento artificial: Do desmame até $24^{\circ}$ mês: $1 \mathrm{mg} / \mathrm{kg} / \mathrm{d}$

RNPT

- A partir de 30 dias: $2 \mathrm{mg} / \mathrm{kg} / \mathrm{d}$

- $4^{\circ}$ ao $24^{\circ}$ mês: $1 \mathrm{mg} / \mathrm{kg} / \mathrm{d}$

A suplementação de ferro pode ser realizada através da administração de sais ferrosos, ferro aminoquelado e o complexo de ferro polimaltosado. ${ }^{42}$ Em termos de absorção, os sais ferrosos são melhores devido à associação da absorção ativa e a passiva, porém o mecanismo de absorção passiva acarreta a liberação de ferro livre no plasma e formação de radicais livres. ${ }^{43} \mathrm{~A}$ fim de não aumentar a produção de radicais livres, a suplementação mais apropriada no prematuro deveria ser feita com complexo de ferro polimaltosado ou aminoquelado. $\mathrm{O}$ tipo de ferro mais comumente utilizado na suplementação, no Brasil, é o sulfato ferroso, medicamento disponibilizado gratuitamente à população. ${ }^{44}$

A dose terapêutica de ferro é indicada quando a concentração sérica de ferritina é abaixo de $100 \mathrm{ng} / \mathrm{dL}$, sendo inicialmente administrados $5-7 \mathrm{mg} / \mathrm{kg} / \mathrm{d}$. Existe relato na literatura de doses de até $15 \mathrm{mg} / \mathrm{kg} / \mathrm{d}$ quando associada ao uso de eritropoetina ${ }^{45}$ Após três a cinco dias de instituído o tratamento, observa-se reticulocitose, que atinge seu pico entre o oitavo e o décimo dia. O aumento da hemoglobina só ocorre após duas semanas, normalizando-se em aproximadamente seis semanas. Para reposição do estoque de ferro são necessários de três a quatro meses de tratamento.

A administração endovenosa de ferro não é habitualmente indicada. Esta via de administração é geralmente utili- zada quando o paciente está em uso de eritropoetina e não apresenta possibilidade de ingestão de ferro por via enteral. A administração intravenosa, na forma de ferro sacarato, se mostrou segura e não parece alterar a absorção enteral de ferro, quando em associação com a via endovenosa ${ }^{46} \mathrm{~A}$ dose na literatura é bastante variável, podendo ser administrados $2 \mathrm{mg} / \mathrm{kg} / \mathrm{d}$ de ferro sucrose, diluídos em soro fisiológico a $0,9 \%$, numa concentração de $2 \mathrm{mg} / \mathrm{ml}$; o período de infusão deve ser de duas horas. ${ }^{39}$ Alguns autores sugerem doses semanais de $6 \mathrm{mg} / \mathrm{kg} / \mathrm{semana}^{.}{ }^{47}$

\section{Abstract}

The main cause of anemia in the fetus is hemolytic disease. Mildly anemic pregnant women may evolve with premature labor and have low birth weight babies, but the baby's iron status is not influenced by the mother's iron deficiency. Iron transportation through the placenta occurs in the third trimester of gestation and premature labor results in reduced iron stores. Iron deficiency anemia does not occur during the neonatal period, but premature and low birth weight babies are at risk of developing iron deficiency. In full-term babies iron deficiency can occur due to intestinal malformation that leads to duodenal resection. To avoid iron deficiency in at-risk babies, iron supplementation is recommended from the thirtieth postnatal day. The best method to avoid iron absorption deficiency in premature babies is the enteral administration of iron. Iron polymaltose complex and amino acidbased iron chelators are preferable to ferrous sulfate in premature babies because of the reduced oxidative side effects of iron administration. Intravenous administration is safe and does not increase the oxidative side effects. Rev. Bras. Hematol. Hemoter. 2010;32(Supl.2):32-37.

Key words: Anemia; iron deficiency; iron; fetus; newborn.

\section{Referências Bibliográficas}

1. Scholl TO, Hediger ML. Anemia and iron-deficiency anemia: compilation of data on pregnancy outcome. Am J Clin Nutr. 1994. 59(2 Suppl):492S-500S.

2. Sifakis S, Pharmakides G. Anemia in pregnancy. Ann N Y Acad Sci. 2000;900:125-36

3. Paiva AP, Rondó PHC, Pagliussi RA, Latorre MROO, Cardoso MAA, Gondim SSR. Relationship between the iron status of pregnant women and their newborns. Rev. Saúde Pública. 2007;41 (3):321-7.

4. Guyton AC: Tratado de fisiologia médica. $6^{a}$ ed. Rio de Janeiro: Guanabara; 1986. p. 50-1.

5. Guidelines for transfusion of erythrocytes to neonates and premature infants. Fetus and Newborn Committee, Canadian Paediatric Society. CMJA. 1992;147(2):1781-92.

6. Dame C, Juul SE. The switch from fetal to adult erythropoiesis. Clin Perinatol. 2000;27(3):507-26.

7. Halperin DS. Use of recombinant erythropoietin in treatment of anemia of prematurity. Am J Pediatr Hematol Oncol. 1991;13(3): 351-63.

8. Jelkmann W. Biology of erythropoietin. Clin Investig. 1994;72(6 Suppl): S3-10. 
9. Lackmann G.M, Schnieder C, Bohner J. Gestational age-dependent reference values for iron and selected proteins of iron metabolism in serum of premature human neonates. Biol. Neonate. 1998;74(3): 208-13.

10. Sigulem DM. Epidemiologia da anemia ferropriva na infância. Rev Soc Bras Hemat Hemot. 1988;10(149):103-7.

11. Vaz FAC. Contribuição ao estudo do metabolismo do ferro em recémnascidos prematuros no primeiro trimestre de vida [Tese Doutorado]. Faculdade de Medicina da Universidade de São Paulo;1971.

12. Strauss RG. Práticas da transfusão de eritrócitos no neonato. In: Bifano M, Ehrenkranz RA. Clínicas de Perinatologia: Hematologia Perinatal. vol 3. Rio de Janeiro: Interlivros; 1995. p. 643-57.

13. Fanaroff AA, Martin RJ. Neonatal, perinatal medicine. Diseases of the fetus and infants. 5 ed. St. Louis: Mosby - yearbook; 1992. p 941-2.

14. Geethanath RM, Ramji S, Thirupuram S, Rao YN. Effect of timing of cord clamping on the iron status of infants at 3 months. Indian Pediatr. 1997;34(2):103-6.

15. Gupta R, Ramji S. Effect of delayed cord clamping on iron stores in infants born to anemic mothers: a randomized controlled trial. Indian Pediatr. 2002;39(2):130-5.

16. Stockman III JA. Anemia of prematurity. Current concepts in the issue of when to transfuse. Pediatr Clin North Am. 1986;33(1): 111-28.

17. Dallman PR. Anemia of prematurity. Annu Rev Med. 1981;32: 143-60

18. O'brien RT, Pearson HA. Physiologic anemia of the newborn infant. J Pediatr. 1971;79(1):132-8.

19. Saito T, Urabe A, Uramoto K, Hashimoto Y, Takaku F. Serum erythropoietin titres in the anaemia of premature infants. Br J Haematol. 1983;54(1):53-8.

20. Collard KJ. Iron homeostasis in the neonate. Pediatrics. 2009; 123(4):1208-16.

21. Joshi A, Gerhardt T, Shandloff P, Bancalari E. Blood transfusion effect on the respiratory pattern of preterm infants. Pediatrics. 1987;80(1):79-84.

22. Strauss RG. Transfusion therapy in neonates. Am J Dis Child. 1991;145(8):04-11.

23. Oski FA, Naiman JL, editors. Hematologic problems in the newborn. $3^{\text {rd }}$ ed. Philadelphia: WB Saunders Co, 1982.

24. Avery GB. Neonatologia, fisiopatologia e tratamento do recémnascido. $2^{\text {nd }}$ ed. Rio de Janeiro: Medsi; 1984. p. 553.

25. Shannon KM, Keith III JF, Mentzer WC, Ehrenkranz RA, Brown MS, Widness JA, et al. Recombinant human erythropoietin stimulates erythropoiesis and reduces erythrocyte transfusions in very low birth weight preterm infants. Pediatrics. 1995;95 (1): $1-8$

26. Schiza V, Giapro V, Pantou K, Theocharis P, Chala A, Andronikous S. Serum transferring receptor, ferritin and reticulocyte maturity indices. Eur J Haematol. 2007;79(5):439-46.

27. Cook JD, Skikne BS, Baynes RD. Serum transferrin receptor. Annu Rev Med. 1993;44:63-74.

28. Punnonem K, Irjala K, Rajamaki A. Serum transferrin receptor and its ratio to serum ferritin in the diagnosis of iron deficiency. Blood. 1997;89(3):1052-7.

29. Cohen A, Manno C. Transfusion practices in infants receiving assisted ventilation. Clin Perinatol. 1998;25(1):97-111.

30. Rodrigues FPM, Berezin A, Percário S. Análise dos radicais livres de oxigênio no período neonatal pela medida dos níveis séricos de malondialdeído e sua correlação com a pO2 sanguínea. Arq méd Hosp Fac Ciênc Méd St Casa São Paulo. 2000;5(1).

31. Murray NA, Roberts IA. Neonatal transfusion practice. Arch Dis Child Fetal Neonatal Ed. 2004;89(2):101-7.
32. Kutner JM, Mota MA, Vacarini ALT, Bub RF. Manual de orientação para o uso de sangue, hemocomponentes e aféreses terapêuticas. $3^{\text {rd }}$ ed. São Paulo: Atheneu; 2003.

33. Maier RF, Obladen MK, Kattner E, Natzschka J, Messer J, Regazzoni BM, et al. High-versus low-dose erythropoietin in extremely low birth weight infants. J Pediatr. 1998;132(5):866-70.

34. Ohls RK. The use of erythropoietin in neonates. In Christensen RD. Clin Perinatol. Neonatal Hematology. 2000;27(3):681-96.

35. Aher S, Ohlsson A. Late erythropoietin for preventing red blood cell transfusion in preterm and/or low birth weight infants. Cochrane Database Syst Rev. 2006;3:CD004868.

36. Ohls RK, Ehrenkranz RA, Wright LL, Lemons JA, Korones SB, Stoll BJ, et al. Effects of early erythropoietin therapy on the transfusion requirements of preterm infants below 1250 grams birth weight: a multicenter, randomized, controlled trial. Pediatrics. 2001;108(4):934-42.

37. Pollak A, Hayde M, Hayn M, Herkner K, Lombard KA. Lubec G, et al. Effect of intravenous iron supplementation on erythropoiesis in erythropoietin-treated premature Infants. Pediatrics. 2001;107 (1):78-85.

38. Fuller NJ, Bates CJ, Cole TJ, Lucas A. Plasma folate levels in preterm infants, with and without a $1 \mathrm{mg}$ daily folate supplement. Eur J Pediatr. 1992;151(1):48-50.

39. Young TE, Mangum B, Reuters T. Neofax. 21st ed. Montvale (NJ): Wiley-Blackwell; 2008. p. 296-313.

40. Arnon S, Shiff Y, Litmanovitz I, Regev RH, Bauer S, ShainkinKestenbaum R, et al. The efficacy and safety of early supplementation of iron polymaltose complex in preterm infants. Am J Perinatol. 2007;24(2):95-100.

41. Sankar MJ, Saxena R, Mani K, Agarwal R, Deorari AK, Paul VK. Early iron supplementation in very low birth weight infants--a randomized controlled trial. Acta Paediatr. 2009;98(6):953-8.

42. Jacobs P, Johnson G, Wood L. Oral iron therapy in human subjects, comparative absorption between ferrous salts and iron polymaltose. J Med. 1984;15(5-6):367-77.

43. Kavakli K, Yilmaz D, Cetinkaya B, Balkan C, Sözmen EY, Sagin FG. Safety profiles of $\mathrm{Fe} 2+$ and $\mathrm{Fe} 3+$ oral preparations in the treatment of iron deficiency anemia in children. Pediatr Hematol Oncol. 2004;21(5):403-10.

44. Tuomainen TP, Nyyssonen K, Porkkala-Sarataho E, Salonen R, Baumgartner JA, Geisser P, et al. Oral supplementation with ferrous sulfate but not with non-ionic iron polymaltose complex increases the susceptibility of plasma lipoproteins to oxidation. Nutrition Research. 1999;19:1121-32.

45. Messer J, Haddad J, Donato L, Astruc D, Matis J. Early treatment of premature infants with recombinant human erythropoietin. Pediatrics. 1993;92(4):519-23.

46. Widness JA, Serfass RE, Haiden N, Nelson SE. Erythrocyte iron incorporation but not absorption is increased by intravenous iron administration in erythropoietin-treated premature infants. J Nutr. 2006;136(7):1868-73.

47. Meyer MP, Haworth C, Meyer JH, Commerford A. A comparison of oral end intravenous iron supplementation in premature infants receiving recombinant erythropoietin. J Pediatr. 1996;129(2): 258-63.

O tema foi sugerido e avaliado pelo coeditor deste fascículo educativo, Rodolfo Cançado, e pelo board interno da RBHH, e publicado após a concordância do editor, Milton Artur Ruiz.

Conflito de interesse: sem conflito de interesse

Recebido: 20/12/2009

Aceito: 15/01/2010 